\title{
INICIAÇÃO ESPORTIVA AO TÊNIS DE CAMPO: UM RETRATO DO PROGRAMA PLAY AND STAY À LUZ DA PEDAGOGIA DO ESPORTE
}

\author{
Caio Correa Cortela, Federação Paranaense de Tênis - FPT, Curitiba, Paraná - Brasil \\ Juan Pedro Fuentes, Universidade de Extremadura - UEX, Cáceres - Espanha \\ Layla Maria Campos Aburachid, Universidade Federal do Mato Grosso - UFMT, Cuiabá, \\ Mato Grosso - Brasil \\ Cesar Kist, Confederação Brasileira de Tênis - CBT, São Paulo, São Paulo - Brasil \\ Débora Navarro Rocha Cortela, Instituto Federal do Paraná - IFPR, Foz do Iguaçu, \\ Paraná-Brasil
}

\section{RESUMO}

O presente estudo procurou através de uma revisão de literatura ampliar os debates sobre a iniciação esportiva ao tênis de campo, contribuindo desta forma para a modificação do cenário atual de ensino da modalidade no Brasil baseado nas metodologias tecnicistas. Para isto, foram apresentados e discutidos, a luz da pedagogia do esporte, os pressupostos teóricos utilizados pelo programa Play and Stay, adotado pela Confederação Brasileira de Tênis como modelo ideal para a iniciação esportiva desta modalidade. A utilização do jogo como elemento central no processo de ensino e aprendizagem, as adaptações nos materiais e o papel central desempenhado pelo aluno permitem a utilização desta metodologia tanto com crianças como para adultos. Após a revisão, verificou-se que o programa em questão apresentou-se como uma ótima alternativa, uma vez que, demonstrou estar em conformidade com as metodologias contemporâneas de ensino dos jogos esportivos como os modelos TGFU e SE.

Palavras-Chave: Tênis; Play and stay; Modelos de ensino; TGFU, Modelo de educação esportiva.

\section{SPORT INITIATION TO TENNIS: AN EXAMPLE OF THE PLAY AND STAY PROGRAM IN THE LIGHT OF THE PEDAGOGY OF THE SPORT}

\begin{abstract}
This study sought through a literature review to expand the debate on sports initiation to tennis, thus contributing to the modification of the current situation of teaching the sport in Brazil based on technical methodology. For this, they were presented and discussed, the light of the pedagogy of sport, the theoretical assumptions used by the Play and Stay program, adopted by the Brazilian Tennis Confederation as the ideal model for the initiation of this sports discipline. The use of the game as a central element in the teaching and learning, adjustments in the materials and the central role played by the student allow the use of this methodology with both children and adults. After review, it was found that


the program in question presented itself as a great alternative, as demonstrated to be in accordance with the methods of teaching contemporary sports as TGFU and SE models.

Key-Words: Tennis; Play and stay; Teaching models; TGFU; Sport education model.

\section{LA INICIACIÓN DEPORTIVA AL TENIS: UN RETRATO DE PLAY AND STAY PROGRAMA A LA LUZ DE LA PEDAGOGÍA DEL DEPORTE}

\section{RESUMEN}

El presente estudio busco, a través de una revisión de la literatura, ampliar los debates sobre la iniciación deportiva en el tenis, contribuyendo de esta forma a la modificación del escenario actual d la enseñanza de esta modalidad en Brasil basándose en las metodologías mecanicistas. Para lo anterior, fueron presentados y discutidos, a la luz de la pedagogía del deporte, los presupuestos teóricos utilizados por el programa Play and Stay, adoptado por la Confederación Brasileña de Tenis como el modelo ideal para la iniciación deportiva de esta modalidad. La utilización del juego como elemento central en el proceso de enseñanza y aprendizaje, las adaptaciones en los materiales y el papel central desempeñado por el alumno permiten la utilización de esta metodología con niños y adultos. Tras la revisión, se verificó que el programa en cuestión se presentó como una óptima alternativa, una vez que, demostró estar en conformidad con las metodologías contemporáneas de enseñanza de los juegos deportivos como los modelos TGFU y SE.

Palabras-Claves: Tenis; Play and stay; Modelos de enseñanza; TGFU, Modelo de educación deportiva. 


\section{INTRODUÇÃO}

O esporte na sociedade contemporânea tem exercido enorme fascínio traduzido em um número cada vez maior de novos adeptos. Na visão de Pimentel, Galatti e Paes ${ }^{1}$ o esporte tem assumido o status de fenômeno globalizador, sendo responsável por uma parcela significativa das movimentações financeiras mundiais e atuando como cenário para distintas manifestações políticas e de poder. Paes e Balbino ${ }^{2}$ relatam que a cultura esportiva tem se difundido de tal forma que atualmente existem mais países filiados ao Comitê Olímpico Internacional do que a Organização das Nações Unidas.

A busca por esta prática remete-se a objetivos distintos, dando ao esporte um significado plural e com diferentes sentidos. Como afirmam Gaya e Torres, ${ }^{3}$ muitas vezes tem-se discutido o esporte apenas pela via mais aparente, o alto rendimento. Segundo os autores, tamanho reducionismo restringe a visão de esporte e o associa a desvios morais como doping e overtraining e a um quadro de referências éticas que em nada o dignificam, não fazendo justiça a grandeza e à sua relevância social, como manifestação sociocultural de múltiplas possibilidades. ${ }^{2,3}$

Desta forma corrobora-se com a visão de que o esporte, para que consiga contemplar sua forma plural, deva ser capaz atender a todas as expectativas dos seus atores. Para isto, Gaya e Torres $^{3}$ e Gaya $^{4}$ sugerem a sua divisão em quatro seguimentos, a saber: esporte de alto rendimento ou excelência; esporte escolar ou como meio para educação; esporte de lazer ou de participação; e esporte e saúde ou de reabilitação e reeducação.

O tênis têm se destacado como uma das modalidades mais praticadas em todo o mundo., Segundo dados apresentados pela International Tennis Federation (ITF), estima-se que aproximadamente um milhão e meio de pessoas pratiquem esta modalidade no Brasil. Estes valores colocam o país em uma posição de destaque para este quesito, ficando a frente de grandes potências como Argentina e Espanha. ${ }^{7}$ As inesquecíveis conquistas do brasileiro Gustavo Kuerten impulsionaram o mercado interno, criando um movimento denominado de "Era Guga", onde se observou um aumento significativo no número de adeptos, bem como no comércio de materiais esportivos ligados a modalidade. ${ }^{8}$

Conexões: revista da Faculdade de Educação Física da UNICAMP, Campinas, v. 10, n. 2, p. 214-234, maio/ago. 2012.216 ISSN: 1983-9030 
No entanto sabe-se que a realidade do tênis no Brasil ainda encontra-se longe da ideal. Como afirmam Muller e Rodrigues, ${ }^{9}$ o tênis ainda é considerado um esporte de elite, sendo restrito a uma pequena parcela da população brasileira de maior poder aquisitivo. A falta de instalações públicas associada à ausência da disciplina tênis de campo na maior parte das universidades brasileiras tem dificultado a disseminação desta modalidade uma vez que, a escassez de profissionais capacitados tem ausentado o tênis do ambiente escolar, deixando de atender uma enorme parcela da população. ${ }^{10}$ Isto explica, em parte, a baixa percentagem de penetração do tênis nas práticas esportivas da população brasileira quando se atenta para os valores relativos.

Segundo dados da ITF, o Brasil ainda encontra-se como um mercado em desenvolvimento para este esporte, observando-se uma taxa de penetração da modalidade em apenas $0,8 \%$ da população, contrastando com valores de $9,5 \%$ e 9,2\% de países consolidados como Austrália e Holanda respectivamente. ${ }^{7}$

Até o momento, o ensino do tênis no Brasil tem ocorrido prioritariamente utilizando-se metodologias tradicionais como a analítica. ${ }^{11,12,13}$ Tais metodologias abrem mão dos aspectos lúdicos do esporte, em prol do desenvolvimento de uma técnica "perfeita", baseando-se em exercícios descontextualizados e fundamentados em um elevado número de repetições, tendo como referencial os padrões técnicos apresentados pelos atletas de sucesso. ${ }^{13}$ De acordo com Greco et al. ${ }^{14}$ e Paula e Balbinotti ${ }^{15}$ este tipo de abordagem promove a exclusão dos indivíduos menos habilidosos e ocasiona a perda de motivação para que sigam praticando o esporte, uma vez que o tempo para se conseguir dominar os gestos técnicos e jogar efetivamente é demasiado longo.

A utilização de metodologias de ensino tradicionais como a analítica também contribuem para o cenário descrito anteriormente sobre a baixa taxa de penetração do tênis entre os brasileiros, tendo em vista que este modelo não permite a participação simultânea de um elevado número de participantes em uma mesma sessão de prática, o que acaba por elevar os custos das aulas e tornar inviável a inserção do tênis no contexto escolar. 
Em contrapartida, as metodologias de ensino contemporâneas como o Teaching Games for Understanding (TGFU) e o Sport Education Model (SE) criticam este ensino descontextualizado, alegando que a iniciação esportiva deveria ocorrer em um contexto complexo e dinâmico como encontrado na prática esportiva, utilizando-se dos jogos reduzidos e a contextualização das situações de jogos para atingir este objetivo. ${ }^{16,17,28,19,20,21,22}$ Neste cenário, a prática através de formas jogadas aparece como um elemento fundamental na iniciação esportiva enfatizando o papel da tomada de decisão e de resolução dos problemas encontrados no jogo de forma criativa. ${ }^{1}$ Corroborando com o acima exposto, Greco et al. $^{23}$ advogam que a iniciação incidental através do jogo apresenta-se como o meio ideal para promover os processos criativos de tomada de decisão e auxiliar no desenvolvimento do pensamento divergente. Diferentemente da metodologia analítica, nesta perspectiva é fundamental que o conhecimento tático seja oferecido antes das habilidades técnicas. ${ }^{14}$

Muitos autores têm contribuído para os debates sobre a pedagogia do esporte e a iniciação esportiva. Particularmente no Brasil, os debates sobre os jogos esportivos coletivos receberam uma contribuição fundamental dos autores portugueses, em especial da Universidade do Porto, como Bento, Garganta, Graça e Mesquita, que em conjunto com autores brasileiros como Balbino, Galatti, Greco, Paes, têm fortalecido a criação de referencial teórico consistente sobre esta temática.

No entanto, o mesmo não se pode afirmar quanto à iniciação esportiva nas modalidades individuais como o tênis. De acordo com, Bolognini e Paes ${ }^{12}$ as produções científicas sobre a iniciação a prática do tênis são escassas e estão voltadas prioritariamente para o ensino dos gestos técnicos. Sem um modelo especificamente delineado para esta finalidade, a Confederação Brasileira de Tênis (CBT) adotou a partir de 2007 o programa Play and Stay (PAS) desenvolvido pela International Tennis Federation (ITF) como metodologia a ser seguida pelos professores nacionais para iniciação esportiva.

O presente trabalho de revisão procurou discutir, a luz da pedagogia do esporte, os pressupostos teóricos que orientam o programa PAS, objetivando ampliar os debates a respeito da iniciação nos jogos esportivos individuais como o tênis, contribuindo para a 
modificação do panorama atual de iniciação esportiva tecnicista em nosso país.

\section{METODOLOGIA}

O presente estudo se desenvolveu a partir de uma revisão de literatura. De acordo com Thomas e Nelson ${ }^{24}$ o propósito deste tipo de trabalho é "usar a literatura para conclusões empíricas e teóricas sem documentar necessariamente a necessidade de um problema de pesquisa determinado". Segundo os autores, uma boa síntese de pesquisa resultará em diversas conclusões tangíveis e deve despertar interesse em direções futuras para a pesquisa. Neste sentido, Marconi e Lakatos ${ }^{25}$ relatam que a pesquisa bibliográfica não é mera repetição do que já foi dito ou escrito sobre certo assunto, mas propicia o exame de um tema sob novo enfoque ou abordagem.

Tendo em vista o acima exposto, este trabalho foi articulado em torno de dois eixos temáticos: um destinado a apresentação de duas metodologias de ensino dos jogos esportivos; $;^{1,2,3,22,26,27}$ e um segundo dedicado a apresentação e discussão das propostas metodológicas utilizadas para o ensino do tênis de. ${ }^{11,13,28,29,30,31,32,33}$

Após a sistematização dos dados apresentados nos trabalhos realizados pelos principais referenciais teóricos deste estudo, procedeu-se a contextualização geral acerca da pedagogia de ensino dos jogos esportivos apresentando os modelos SE e TGFU. Posteriormente apresentou-se o programa PAS como alternativa à iniciação ao tênis de campo, procurando debater especificamente as bases conceituais apresentadas pelo programa frete os princípios teóricos apresentados pela pedagogia do esporte.

\section{DESENVOLVIMENTO}

Iniciação esportiva: um breve relato sobre os modelos de Educação Esportiva e o Ensino dos Jogos para Compreensão.

A utilização de metodologias tradicionais como linhas norteadoras da iniciação esportiva têm sido alvo constante de críticas pela literatura contemporânea., ${ }^{2,22}$ A ênfase Conexões: revista da Faculdade de Educação Física da UNICAMP, Campinas, v. 10, n. 2, p. 214-234, maio/ago. 2012. 219 ISSN: 1983-9030 
demasiada dada pelas abordagens tecnicistas ao desenvolvimento das habilidades técnicas, obtidas através de um elevado número de repetições; a fragmentação do jogo traduzida no ensino dissociado e descontextualizado dos elementos técnicos e táticos; e o papel secundário desempenhado pelo aluno no processo de ensino-aprendizagem apresentam-se como os pontos mais criticados destes modelos de ensino. ${ }^{11,12,13,27,34}$

Com o intuito de superar as fragilidades apresentadas pela abordagem tecnicista, Mesquita et al. ${ }^{27}$ destacam que em meados das décadas de 60 e 70 do século passado, iniciou-se um movimento reformador do ensino dos jogos. Tendo como pano de fundo as abordagens construtivistas e cognitivistas, este movimento passou a partir da década de 90 a ser tema frequente nas agendas da literatura relacionada ao ensino da educação física. ${ }^{22,27}$ Neste cenário, os modelos de Educação Esportiva elaborado por Siedentop e o Ensino dos Jogos para Compreensão idealizados por Bunker e Thorpe ganharam destaque nas publicações dos autores luso-brasileiros. ${ }^{3,13,26,33,34}$

De acordo com Graça e Mesquita, ${ }^{22}$ o modelo de Educação Esportiva (SE) foi desenvolvido na tentativa de contextualizar o jogo enquanto elemento lúdico e capaz de auxiliar na educação e na formação dos praticantes, valorizando desta forma as dimensões humana e cultural do esporte. Neste sentido, o modelo em questão apresenta uma diferença essencial em relação às abordagens tradicionais, uma vez que enfatiza a preocupação em reduzir ao máximo os fatores de exclusão, favorecendo a participação de todos. ${ }^{22,33}$

Para cumprir com estes objetivos os autores sugerem a criação de épocas esportivas, onde as crianças estejam filiadas a uma equipe. A criação das equipes adolesce o sentimento de pertencer ao grupo e conjuntamente com a competição formal previamente marcada para o final da época esportiva, corrobora para que todos os integrantes trabalhem em grupo em prol da equipe. O papel desempenhado pelos alunos nesta abordagem não se limita à participação enquanto jogadores, oportunizando experiências em posições de liderança como treinadores, árbitros, jornalistas, entre outros. A avaliação dos alunos no SE ganha significado, uma vez que ocorre de forma contextualizada e ao longo de todo o processo de ensino-aprendizagem, oportunizando feedback individuais e especificamente orientados à capacidade de jogar. ${ }^{34,13}$ 
Espera-se com este modelo formar indivíduos esportivamente competentes, cultos e entusiastas. Competente, neste contexto, refere-se a aquele sujeito que domina satisfatoriamente as habilidades necessárias, sendo capaz de adotar comportamentos táticos condizentes com o seu nível de jogo e participar efetivamente durante a prática. Quanto à expressão culto, refere-se ao sujeito que conhece, valoriza as tradições e os rituais associados ao esporte e que distingue a boa da má prática esportiva. Por entusiasta compreende-se que seja o sujeito que é atraído pelo o esporte e que é um promotor da qualidade e um defensor da autenticidade deste fenômeno. ${ }^{19}$

Quanto ao modelo de Ensino dos Jogos para Compreensão (TGFU), este tem como objetivo principal o desenvolvimento da capacidade de jogo, obtido através da compreensão tática do mesmo. Tendo como elemento central do processo de ensino e aprendizagem a utilização de jogos reduzidos como meio para a construção do conhecimento, o TGFU apresenta o jogo como espaço para a resolução de problemas, enfatizando os componentes cognitivos presentes na prática. Neste sentido, observa-se uma clara preocupação por parte do TGFU de que os componentes táticos presentes no jogo sejam ensinados previamente aos elementos técnicos, no intuito de contextualizar o ensino e de não apresentar as habilidades técnicas como finalidade, como observado na abordagem tradicional. ${ }^{26,34}$

Segundo Bolonhini e Paes, ${ }^{26}$ para que o conhecimento seja efetivamente construído, é fundamental que os professores propiciem aos alunos momentos de debates, onde os mesmos possam refletir criticamente sobre a prática e desta forma elaborarem novas estratégias de atuação para os jogos posteriores. Assim, verifica-se que o papel do aluno no processo de ensino-aprendizagem neste modelo é modificado, deixando de participar meramente como um reprodutor das atividades propostas pelo professor, para tornar-se o elemento central do processo, sendo estimulado a adotar uma postura crítica em relação a sua participação e ao desenvolvimento da aula. ${ }^{22,26,27}$

Para que o jogo deixasse de ser um mero momento de aplicação dos gestos técnicos para transformar-se em um espaço de resolução de problemas, foram necessárias adaptações 
baseadas em quatro princípios pedagógicos utilizados pelo TGFU: seleção do tipo de jogo (articulação coerente das formas de jogo com a finalidade de facilitar o desenvolvimento da aprendizagem e a transferência de estratégias de leitura entre jogos com princípios em comum); modificação do jogo por representação (apresentação de formas simplificadas e reduzidas do jogo que mantenham a essência das estruturas táticas que o configuram, devendo as mesmas serem uma representação do jogo formal); modificação do jogo por exagero (manipulação das regras, do espaço e do tempo de jogo na tentativa oportunizar um maior número de confrontos com determinadas situações táticas ou para o desenvolvimento de ações motoras específicas); ajustamento da complexidade tática (seleção e progressão das situações de jogo objetivando ajustar os problemas táticos ao repertório motor dos alunos para que os mesmos consigam incrementar e atuar efetivamente durante o jogo) Holt et al. (2002, apud GRAÇA; MESQUITA). ${ }^{22}$

Assim como relatam Graça e Mesquita, ${ }^{22}$ observa-se que o SE e o TGFU apresentam pontos fortes de aproximação, observando-se uma crítica aos modelos de múltiplas atividades, pelo seu caráter descontextualizado e o apelo ao jogo reduzido como meio para iniciação aos jogos esportivos. Constatam-se ainda, a preocupação de ambas as abordagens para que o aprendizado dos gestos técnicos decorra da necessidade de se melhorar a atuação enquanto sujeito ativo que participa do jogo, reforçando-se a necessidade de que o conhecimento tático seja oferecido antes das habilidades técnicas.

Por fim, destaca-se nos dois modelos o papel central desempenhado pelo aluno como elemento ativo no processo de ensino-aprendizagem e co-responsável pela construção do conhecimento.

\section{A iniciação esportiva no Tênis de Campo}

Semelhantemente a iniciação esportiva dos jogos coletivos, observa-se até o momento que a iniciação ao tênis tem ocorrido baseada no modelo tecnicista de ensino. ${ }^{11,35,36,37}$ Assim, Balbinotti ${ }^{11}$ afirma que é comum observar-se nas quadras tênis a figura proeminente do professor enquanto detentor e centralizador do conhecimento, ensinando e corrigindo os gestos motores na busca de uma técnica considerada perfeita. Nesta direção, Reid et al., ${ }^{30}$ destacam que tradicionalmente os treinadores de tênis têm priorizado o ensino dos 
gestos técnicos, optando por apresentar os componentes táticos somente após o domínio técnico das habilidades encontradas no jogo. De acordo com os autores, embora essa abordagem possa facilitar a aquisição de habilidades nas etapas iniciais, sua transferência para a realidade encontrada no jogo tem sido amplamente questionada.

Cientes das dificuldades e do tempo gasto para se dominar por completo os gestos técnicos, e preocupada com a o abandono da prática por parte dos indivíduos menos habilidosos, a ITF após a criação de um grupo de estudos, lançou no ano de 2007 um programa denominado de Play and Stay (PAS). De acordo com Milley ${ }^{38}$ o PAS tem como objetivo principal fazer com que desde a primeira aula os alunos sejam capazes de jogar: sacando, trocando bolas e pontuando.

Com um enfoque baseado no jogo, em situações de jogos reduzidos e contextualizadas, e na utilização de materiais adaptados (três diferentes tipos de bolas de baixa pressão e quadras reduzidas, e raquetes menores), o PAS padronizou e sistematizou os elementos básicos utilizados na prática do Mini-Tênis, traduzindo para a realidade da modalidade os conceitos chaves do TGFU. De acordo com Unierzyski e Crespo ${ }^{39}$ a utilização de equipamentos adaptados torna o aprendizado do tênis mais fácil, oportunizando o desenvolvimento de um padrão de jogo completo, o uso correto das técnicas e a redução dos riscos de lesão. Porém, aqueles que acreditam que a utilização de materiais adaptados no tênis seja algo recente estão enganados. O Mini-Tênis, precursor do PAS, foi amplamente utilizado e divulgado na década de 1980 pelas potências mundiais como a Alemanha, os EUA e a França. Crespo ${ }^{40}$ refere haver relatos de uma demonstração de Hold e Van der Meer de tênis em dimensões reduzidas já em 1955, na Tchecoslováquia.

Dentro do programa, as bolas de baixa pressão têm recebido grande atenção sendo consideradas peças chaves no desenvolvimento dos tenistas. ${ }^{29,38}$

Segundo Martens e De Vylder ${ }^{41}$ e $\mathrm{Newman}^{32}$ as bolas mais lentas proporcionam mais tempo para resposta, facilitando as trocas de bolas e auxiliando no desenvolvimento avançado da tática e da técnica. Neste sentido, Farrow e Reid ${ }^{31}$ relatam que as razões que justificariam a utilização dos materiais adaptados para as crianças estão relacionadas à melhoria na aquisição das habilidades técnicas e pelo aumento na motivação dos 
praticantes, resultando em uma maior probabilidade dos mesmos seguirem engajados na prática esportiva.

Segundo Newman, ${ }^{32}$ o desenvolvimento das bolas de baixa pressão levou em consideração a proporção do ressalto realizado pela bola convencional após o quique perante um adulto e o adaptou proporcionalmente à estatura das crianças. Considerando que o ponto ideal para se golpear a bola do fundo da quadra encontra-se entre a cintura e o ombro, observouse que frequentemente as bolas tradicionais quando utilizadas pelas crianças ultrapassavam a altura da cabeça, ocasionando problemas táticos, decorrentes da adaptação da forma de jogo a situação problema e deficiências técnicas acarretadas pela utilização de empunhaduras extremas. Nesta mesma direção, Kibler ${ }^{42}$ advoga que a utilização destas empunhaduras incrementa os ricos de lesão no braço, limitando ainda a capacidade do jogador de controlar a bola e de ser ofensivo.

Após a aplicação de oito sessões de treino em crianças com idades entre cinco e 11 anos, Hammond e Smith $^{28}$ descreveram que os treinadores responsáveis pela execução dos programas relataram o aprendizado correto dos gestos técnicos praticados (saque, forehand e backhand), um maior número de trocas de bolas, bem como um maior reforço positivo por parte dos alunos que utilizaram as bolas de baixa pressão, destacando a importância da utilização deste material para as crianças em estágios iniciais de aprendizagem.

Contrastando com a afirmação divulgada pela ITF de que a utilização das bolas de baixa pressão é a grande chave do PAS, Farrow e Reid ${ }^{31}$ relataram em seu estudo que as dimensões da quadra exercem efeito relativamente maior na aprendizagem do que as bolas modificadas. Através de um estudo realizado com crianças de escola primária, os autores verificaram que os grupos que realizaram as sessões de prática com bolas e quadras convencionais apresentaram resultados inferiores, verificando-se menores oportunidades de executarem os golpes de forehand e backhand, menores taxas de sucesso nas execuções de forehand e menor engajamento na prática esportiva.

Segundo Newman ${ }^{32}$ as quadras reduzidas adaptadas a morfologia das crianças permitem a utilização de padrões de movimentos mais realistas, possibilitando aos jovens tenistas 
cobrirem toda a quadra e implementarem táticas avançadas. Em uma quadra oficial de tênis, as crianças raramente têm a possibilidade de executar com êxito as jogadas de rede como o voleio, o smash e o bate-pronto, considerando que a baixa estatura apresentada faz com que a maior parte das bolas rebatidas do fundo da quadra acabem passando sobre a zona de impacto alcançada pelas mesmas.

Tendo em vista que a fase motora especializada é considera o período sensível para o aprendizado e desenvolvimento das habilidades esportivas, como assim o consideram Gallahue e Ozmun, ${ }^{43}$ a falta de êxito em algumas jogadas básicas do tênis como o jogo de rede acarretadas pela estatura relativamente baixa, podem desencorajar a utilização deste tipo de jogada durante os jogos, ocasionando deficiências técnicas que podem vir a comprometer a formação de um padrão de jogo completo na idade adulta. Como relatam Ré e Barbanti" "o que Pedrinho não aprendeu, será ainda mais difícil para Pedro aprender".

As modificações proposta pelo PAS não se restringem aos materiais. Assim como no TGFU e no SE a metodologia de ensino utilizada pelo PAS pauta-se nos princípios construtivistas e cognitivistas, dando ao aluno um papel central no processo de construção do conhecimento e das habilidades técnicas, utilizando-se de jogos reduzidos e contextualizados como meio para o ensino deste esporte. ${ }^{39}$

Igualmente advogam Graça e Mesquita $^{22}$ ao descreverem que o jogo em sua forma modifica é a referência central do processo de ensino e aprendizagem dos jogos esportivos, Miley ${ }^{38}$ destaca que o enfoque baseado no jogo é base para todos os níveis de treinamento no tênis, sendo fundamental para o sucesso do programa PAS.

Sobretudo com crianças nas etapas de formação, Bolaños et al. ${ }^{45}$ descrevem que o método estrutural baseado no TGFU é considerado a estratégia mais vantajosa para lidar com as situações imprevisíveis do esporte, visando propiciar uma aprendizagem construtivista. A simplificação das regras aliada à adaptação dos materiais é fundamental para o aumento da motivação com a prática. Com dimensões físicas e regras adaptadas à criança, ela passará a enfocar o jogo em vez de se preocupar em executar as habilidades. Neste sentido o 
aprendizado ocorrerá por meio de jogos e não somente pela prática repetitiva de gestos técnicos. ${ }^{13}$

Segundo Bolonhini e Paes, ${ }^{26}$ os jogos reduzidos envolvem um contexto complexo que possibilita uma variada vivência motora, exige a aplicação de diferentes técnicas e a estruturação de táticas para solucionar as dificuldades que o mesmo propicia. Assim, de acordo com Ré e Barbanti, ${ }^{44}$ a imprevisibilidade de ações encontradas nos esportes de habilidades abertas como o tênis, faz com que os alunos necessitem vivenciar situações abertas no contexto diário de prática na tentativa de aprimorar os mecanismos perceptivos e decisórios. Neste sentido, como relatado por Paes e Balbino, ${ }^{2}$ acredita-se que é preciso jogar para aprender e não aprender para jogar, observando-se uma clara inversão no papel desempenhado pelo jogo quando comparado a metodologia tradicional de ensino.

Muitos treinadores questionam a eficiência do aprendizado da técnica nos programas que se utilizam prioritariamente dos jogos como meio para a iniciação esportiva. Em seu trabalho com crianças escolares Píffero e Valentini ${ }^{33}$ destacaram que tanto a abordagem clássica como a abordagem baseada no SE e no Contexto Motivacional para a Maestria promoveram melhorias significativas nas habilidades motoras especializadas do tênis. Porém, as autoras relataram que, para além das melhorias nas habilidades específicas, os alunos da abordagem motivacional apresentaram uma associação estatisticamente significativa entre estas habilidades e a habilidade fundamental de locomoção, não sendo relatados os mesmos efeitos para a abordagem clássica. Nesta mesma direção, Canfield e $\mathrm{Netto}^{46}$ descreveram que as crianças que participam de situações de aprendizagem com maior incerteza ambiental apresentaram resultados superiores nas tarefas de rebater, reforçando a importância de se propiciar durante as práticas, situações onde as mesmas tenham de solucionar problemas motores, abdicando do papel de meras reprodutoras de movimentos estereotipados.

Tendo em vista o quadro anteriormente descrito questiona-se o porquê dos professores de tênis ainda optarem pelas metodologias tradicionais, uma vez que, o ensino baseado nos jogos tem apresentado resultados similares para a aquisição das habilidades técnicas e propiciado uma maior motivação por parte das crianças para a prática nas fases iniciais de 
aprendizagem. Não se coloca em xeque a importância dos drills e da repetição para o desenvolvimento dos gestos técnicos no tênis. No entanto, como argumenta Young (1985, apud Piffero e Valentini), ${ }^{33}$ em contraste com os alunos mais habilidosos, os iniciantes não valorizam este tipo de prática, pois somente encontram prazer no jogo em si.

As adaptações propostas pela metodologia do PAS não se restringem apenas às crianças e jovens. O tênis apresenta um grande número de indivíduos que iniciam a prática da modalidade tardiamente. $\mathrm{O}$ fato de ser um esporte praticado ao ar livre associado à facilidade de encontrar parceiros para jogar, faz com que muitos adultos que nunca tiveram contato com a modalidade elejam o tênis como um meio para obtenção de níveis satisfatórios de atividade física. Diversos estudos têm relatado os benefícios da prática desta modalidade independentemente do nível técnico dos praticantes. ${ }^{47,48,49}$

De acordo com Pimentel, Galatti e Paes ${ }^{1}$ apesar dos jovens adultos poderem apresentar algumas restrições nos movimentos que possam retardar o aprendizagem dos gestos técnicos nas etapas iniciais, o maior desenvolvimento cognitivo permite a esta população uma maior compreensão e capacidade de solucionar os problemas táticos complexos encontrados no jogo. Nesta direção Doolittle ${ }^{50}$ acrescenta que nas etapas iniciais de aprendizado os indivíduos menos habilidosos vivenciam o sucesso na atividade nos aspectos cognitivos que compõe o jogo. Desta forma, assim como preconiza o PAS, Pimentel, Galatti e Paes ${ }^{1}$ descrevem que a maior capacidade de entendimento e de leitura do jogo por parte destes alunos faz das situações de jogo e o jogo propriamente dito, as melhores estratégias para a iniciação esportiva tardia.

\section{CONSIDERAÇÕES FINAIS}

De acordo com o levantamento realizado, o PAS apresentou-se como uma ótima opção para iniciação esportiva ao tênis, uma vez que demonstrou estar em conformidade com os pressupostos apresentados pelas metodologias contemporâneas de ensino dos jogos esportivos como TGFU e SE.

A utilização do jogo como elemento central no processo de ensino e aprendizagem, as adaptações nos materiais e o papel de destaque desempenhado pelo aluno permitem a 
utilização desta metodologia tanto com crianças como para adultos. A preocupação em fazer com que desde as primeiras aulas os alunos sejam capazes de jogar (sacando, trocando bolas e pontuando) suscita a necessidade de priorizar, em um primeiro momento, os aspectos táticos do jogo, enfatizando o trabalho da técnica após a compreensão do aluno do papel desempenhado pela mesma como ferramenta para solucionar os problemas encontrados no jogo.

Especificamente para as crianças, as mudanças nos materiais e nos formatos de competições foram tão fortes com a entrada do programa, que a partir de 2012 os mais de 200 países filiados a ITF deverão abolir a utilização das bolas de tênis tradicionais para as competições entre tenistas menores de 10 anos de idade.

Muitos outros programas com características similares as do PAS têm sido desenvolvido pelas potências mundiais do tênis como o Quick Start, o Ariel, o French Mini Tennis. Tendo em vista a realidade brasileira, verifica-se a necessidade de um maior número de estudos que justifiquem a progressão dos três tipos de bolas propostas pelo programa, uma vez que, a redução no número de bolas utilizadas para a iniciação poderá reduzir os custos advindos na compra dos materiais, contribuindo para a acessibilidade ao material de prática.

Para além dos benefícios citados anteriormente, as adaptações metodológicas apresentadas pelo PAS permitem a participação simultânea de um maior número de pessoas nas aulas possibilitando, desta forma, a redução dos valores cobrados pelas mesmas desmistificando o tênis enquanto esporte de elite e restrito às classes socioecômicas de maior poder aquisitivo. Estas alterações permitem ainda a inserção do tênis no ambiente escolar, oportunizando as crianças conhecer esta modalidade esportiva em que o Brasil, por um período de tempo significativo, teve o melhor atleta do mundo.

\section{REFERÊNCIAS}

${ }^{1}$ PIMENTEL, R. M.; GALATTI, L. R.; PAES, R. R. Pedagogia do esporte e iniciação

Conexões: revista da Faculdade de Educação Física da UNICAMP, Campinas, v. 10, n. 2, p. 214-234, maio/ago. 2012. 228 ISSN: 1983-9030 
esportiva tardia: perspectivas a partida da modalidade basquetebol. Pensar a Prática, Goiânia, v.13, n.1, p 1-15, jan./abr. 2010.

${ }^{2}$ PAES, R. R.; BALBINO, H. F. A pedagogia do esporte e os jogos coletivos. In: DE ROSE, D. et al. Esporte e atividade física na infância e adolescência: uma abordagem multidisciplinar. Porto Alegre: Artmed, 2009. p. 73-83.

${ }^{3}$ GAYA, A.; TORRES, L. O esporte na infância e adolescência: alguns pontos polêmicos. In GAYA, A.; MARQUES, A.; TANI, G. Desporto para crianças e jovens: razões e finalidades. Porto Alegre: Ed. da UFRGS, 2004. p. 57-74.

${ }^{4}$ GAYA, A. Corpos esportivos: O esporte como campo de investigação científica. In: TANI, G.; BENTO, J. O.; PETERSEN, R. D. S. Pedagogia do desporto. Rio de Janeiro: Guanabara Koogan, 2006. p. 101-112.

${ }^{5}$ CRESPO, M. Las potencias mundiales del tenis: razones del éxito, 2006. Disponível em: 〈http://www.itftennis.com/shared/medialibrary/pdf/original/IO_7238_original.PDF>. Acesso em: 20 ago. 2007.

${ }^{6}$ PLUIM, B. M. et al. Tennis injuries: occurrence, aetiology, and prevention. British Journal of Sports Medicine, Londres, v. 40, n. 5, p. 415-423, 2006.

${ }^{7}$ FEDERAÇÃO INTERNACIONAL DE TÊNIS (ITF). Tennis beyond 2000. Disponível em: < http://www2.uol.com.br/tenisbrasil/especiais/tenis2000.htm>. Acesso em: 03 maio 2007.

${ }^{8}$ MUELLER, J.; MIRANDA, M. Tênis. In DA COSTA, L. Atlas do esporte no Brasil. Rio de Janeiro: Shape, 2006. p. 8.70-8.72.

${ }^{9}$ MUELLER, J.; RODRIGUES, O. A. F. O tênis nas escolas: uma prática apropriada a cultura escolar. In: BALBINOTTI, C. et al. O ensino do tênis: novas perspectiva de aprendizagem. Porto Alegre: Artmed, 2009. p. 61-79.

Conexões: revista da Faculdade de Educação Física da UNICAMP, Campinas, v. 10, n. 2, p. 214-234, maio/ago. 2012.229 ISSN: 1983-9030 
${ }^{10}$ DIAS, J. M. et al. O ensino e aprendizagem de Tênis nos cursos de Educação Física. In: JORNADA INTERNACIONAL DE TREINAMENTO E ORGANIZAÇÃO DO TÊNIS, 4. Florianópolis, 2002. Anais... Florianópolis: NETEC, 2002. p. 105-107.

${ }^{11}$ BALBINOTTI, C. O ensino do tênis de campo: o processo de aprendizagem progressiva. In: TANI, G.; BENTO, J. O.; PETERSEN, R. D. S. Pedagogia do desporto. Rio de Janeiro: Guanabara Koogan, 2006. p. 399-407.

${ }^{12}$ BOLOGNINI, S. Z; PAES, R. R. Propostas pedagógicas e o tênis de campo: confronto entre teoria e prática. Motriz, Rio Claro, v.13, n. 2, p. 70, maio/ago. 2007.

${ }^{13}$ VALENTINI, N. et al. Considerações sobre o desenvolvimento e a aprendizagem motora em crianças. In: BALBINOTTI, C. et al. O ensino do tênis: novas perspectivas de aprendizagem. Porto Alegre: Artmed, 2009. p. 29-45.

${ }^{14}$ GRECO, J. P.; SILVA, S. A.; ABURACHID, L. C. Iniciação esportiva universal: uma escola da bola aplicada ao tênis. In: BALBINOTTI, C. et al. O ensino do tênis: novas perspectivas de aprendizagem. Porto Alegre: Artmed, 2009a. p. 80-97.

${ }^{15}$ PAULA, P. R.; BALBINOTTI, C. Iniciação ao tênis na infância: os primeiros contatos com a bola e a raquete. In: BALBINOTTI, C. et al. O ensino do tênis: novas perspectivas de aprendizagem. Porto Alegre: Artmed, 2009. p. 15-28.

${ }^{16}$ FUENTES, J. P.; GUSI, N. Iniciación jugada a la técnica y a la táctica en el tenis: espacios reducidos y poco material. Cáceres: Copegrafm, 1996.

${ }^{17}$ FUENTES, J. P. G.; VILLAR, F. D. A. El tenis en el currículum de Educación Física en el Bachillerato. Unidad didáctica: "Aprendizaje del tenis y mejora del sentido técnicotáctico a través de su práctica adaptada . In: FUENTES, J. P. Enseñanza y entrenamiento del tenis: fundamentos didácticos y científicos. Cáceres: Universidad de Extremadura, 1999. p. 72-107.

Conexões: revista da Faculdade de Educação Física da UNICAMP, Campinas, v. 10, n. 2, p. 214-234, maio/ago. 2012.230 ISSN: 1983-9030 
${ }^{18}$ BRECHBÜHL, J.; ANKER, P. El método de acción en el tenis. ITF Coaches Review, v. 22, p. 7-10, 2000.

${ }^{19}$ GRAÇA, A. O desporto na escola: enquadramento da prática. In: GAYA, A.; MARQUES, A.; TANI, G. Desporto para crianças e jovens: razões e finalidades. Porto Alegre: Ed. da UFRGS, 2004. p. 97-112.

${ }^{20}$ SANZ, D. et al. Desarrollo de las unidades didácticas. In: SANZ, D. El tenis en la escuela. Barcelona: Paidotribo, 2004. p. 157-230.

${ }^{21}$ TORRES, G.; CARRASCO, L. EI tenis en la escuela. Barcelona: Inde, 2005.

${ }^{22}$ GRAÇA, A.; MESQUITA, I. A investigação sobre os modelos de ensino dos jogos desportivos. Revista Portuguesa de Ciências do Desporto, Porto, v.7, n.3, p. 401-421, dez. 2007.

${ }^{23}$ GRECO, J. P.; SILVA, S. A.; ABURACHID, L. C. Processos cognitivos: interação com o treinamento tático no tênis. In: BALBINOTTI, C. et al. O ensino do tênis: novas perspectivas de aprendizagem. Porto Alegre: Artmed, 2009b. p. 163-177.

${ }^{24}$ THOMAS, J. R.; NELSON, J. K. Métodos de pesquisa em atividade física. 3. ed. Porto Alegre: Artmed, 2002.

${ }^{25}$ MARCONI, M. A.; LAKATOS, E. M. Fundamentos da metodologia científica. 7. ed. São Paulo: Atlas, 2010.

${ }^{26}$ BOLONHINI, S. Z.; PAES, R. R. A proposta pedagógica do teaching games for understanding: reflexões sobre a iniciação esportiva. Pensar a Prática, Goiânia, v.12, n. 2, p.1-9, 2009.

${ }^{27}$ MESQUITA, I. M. R.; PEREIRA, F. R. M.; GRAÇA, A. B. S. Modelos de ensino dos jogos desportivos: investigação e ilações para a prática. Motriz, Rio Claro, v.15, n. 4, p. 
944-954, out./dez. 2009.

${ }^{28}$ HAMMOND, J.; SMITH, C. Low compression tennis balls and skill development. Journal of Sports Science and Medicine, Turquia, v. 5, p. 575-581, 2006.

${ }^{29}$ MILLEY, D. Tennis: play and stay. ITF Coaches Review, v. 42, p. 2-3, 2007.

${ }^{30}$ REID, M. et al. Skill acquisition in tennis: research and current practice. Journal of Science and Medicine in Sport, Belconnen, v. 10, p. 1-10, 2007.

${ }^{31}$ FARROW, D.; REID. M. The effect of equipment scaling on the skill acquisition of beginning tennis players, Journal of Sports Sciences, Inglaterra, v. 28, n. 7, p. 723 -732, 2010.

${ }^{32}$ NEWMAN, J. Why slower balls and smaller courts for 10 and under players? ITF Coaches Review, v. 51, p. 5-7, 2010.

${ }^{33}$ PÍFFERO, C. M.; VALENTINI, N. C. Habilidades especializadas do tênis: um estudo de intervenção na iniciação esportiva com crianças escolares. Revista Brasileira de Educação Física e Esporte, São Paulo, v. 24, n. 2, p.149-63, abr./jun. 2010.

${ }^{34}$ MESQUITA, I.; GRAÇA, A. Modelos de ensino dos jogos desportivos. In: TANI, G.; BENTO, J. O.; PETERSEN, R. D. S. Pedagogia do desporto. Rio de Janeiro: Guanabara Koogan, 2006. p. 267-283.

${ }^{35}$ CRESPO, M.; MIRANDA, M. A. Evolución de la metodología en la enseñanza del tenis. Educación Física, Chile, v. 255, p.16-21, 2001.

${ }^{36}$ TURNER, A. et al. El enfoque de la comprensión del juego aplicado a la enseñanza del tenis. ITF Coaches Review, v. 26, p. 2-3, 2002.

${ }^{37}$ CARRERAS, J. C.; GIMÉNEZ, J. Metodología de enseñanza utilizada en la enseñanza 
del tenis durante la etapa de iniciación. Retos: nuevas tendencias en Educación Física, deporte y recreación, v. 18, p. 60-65, 2010.

${ }^{38}$ MILLEY, D. Serve rally and score: the ITF tennis play and stay campaign and tennis $10 \mathrm{~s}$. ITF Coaches Review, v. 51, p. 3-5, 2010.

${ }^{39}$ UNIERZYSKI, P.; CRESPO, M. Review of modern teaching methods for tennis. Revista Internacional de Ciencias del Deporte. v. 7, n. 3, p. 1-10, 2007.

${ }^{40}$ CRESPO, M. Mini-tenis un medio para el aprendizaje del tenis. Apunts, v. 44/45, p. $42-$ $50,1996$.

${ }^{41}$ MARTENS, S.; DE VYLDER, M. The use of low compression balls in the development of high performance players. ITF Coaches Review, v. 42, p. 3-5, 2007.

${ }^{42}$ KIBLER, W. B. Specific problems for the young tennis player. In: RENSTRÖM, P. A. F. H. Handbook of Sports Medicine and Science: tennis. Oxford: Blackwall Science, 2002. p. 139-146.

${ }^{43}$ GALLAHUE, D. L.; OZMUN, J. C. Compreendendo o desenvolvimento motor: bebês, crianças, adolescentes e adultos. 2. ed. São Paulo: Thorpe, 2003.

${ }^{44}$ RÉ, A. H. N.; BARBANTI, V. J. Uma visão macroscópica da influência das capacidades motoras no desempenho. In: SILVA, L. R. R. Desempenho esportivo: treinamento com crianças e jovens. São Paulo: Phorte, 2006. p. 217-240.

${ }^{45}$ BOLAÑOS, M. A. C. et al. Métodos de ensino nos jogos esportivos. Movimento \& Percepção, Espírito Santo do Pinhal, v. 10, n. 15, jul/dez. 2009.

${ }^{46}$ CANFIELD, M. S.; NETTO, C. A. F. Aprendizagem da tarefa de rebater sob duas condições diferentes de incerteza ambiental, em crianças de 6 a 9 anos de idade. Revista Brasileira de Ciencias do Esporte, Campinas, v. 16, n. 2, p. 114-121, 1995. 
${ }^{47}$ FERRAUTI, A.; WEBER, K.; STRÜDER, H. K. Effects of tennis training on lipid metabolism and lipoproteins in recreational players. British Journal of Sports Medicine, Londres, v. 31, n. 4, p. 322-327, 1997.

${ }^{48}$ FERNANDEZ, J. F. F.; VILLANUEVA, A. M.; PLUIM, B. M. Intensity of tennis match play. British Journal of Sports Medicine, Londres, v. 40, n. 5, p. 387-391, 2006.

${ }^{49}$ MARKS, B. L. Health benefits for veteran (senior) tennis players. British Journal of Sports Medicine, Londres, v. 40, n. 5, p. 469-476, 2006.

${ }^{50}$ DOOLITTLE, S. Teaching net games to skilled students: a teaching for understanding approach. Journal of Physical Education, Recreation and Dance, Reston, v. 66, n. 3, p. 18-23, 1995.

Recebido em: 12 março 2012 Aceito em: 01 junho 2012 